\title{
Anesthetic Management for Transverse Colostomy in a Neonate with Anorectal Malformation and Uncorrected Tetralogy of Fallot
}

\author{
S Indumathi ${ }^{1}$, Raviraj Kamble ${ }^{2}$, Pritam Adsule ${ }^{3}$, Pradnya M Bhalerao ${ }^{4}$
}

\begin{abstract}
Tetralogy of fallot (TOF) is a cyanotic congenital heart disease (CHD) characterized by aortic over riding, right ventricular outflow tract (RVOT) obstruction, pulmonary stenosis, and ventricular septal defect (VSD). We report a case of a neonate with TOF and anorectal malformation posted for a transverse colostomy. During this procedure, our objectives were to prevent cyanotic spells, balance pulmonary vascular resistance, and systemic vascular resistance.

Keywords: Anesthesia, Colostomy, Tetralogy of Fallot.

Research and Innovation in Anesthesia (2019): 10.5005/jp-journals-10049-0056
\end{abstract}

\section{INTRODUCTION}

Tetralogy of fallot (TOF) is a cyanotic congenital heart disease (CHD) with an incidence of 3 in 10,000 births characterized by aortic overriding, right ventricular outflow tract (RVOT) obstruction, pulmonary stenosis, and ventricular septal defect (VSD). ${ }^{1}$

Among them, 30\% require surgery during the first year of life for extracardiac abnormalities, which are grouped as VACTERL ( $V$, vertebral defects; $A$, anal atresia; $C$, cardiac anomalies; $T$, tracheoesophageal fistula; $R$, renal anomalies; and $L$, limb abnormalities) or CHARGE syndrome (C, coloboma; $\mathrm{H}$, heart defects; $\mathrm{A}$, atresia of choanae; $R$, retarded growth; $G$, genital abnormalities; and $E$, ear abnormalities). Hence the presence of one anomaly necessitates to rule out all other associated anomalies. The most common structural malformation associated with congenital heart disease is gastrointestinal anomalies. As the neonates and infants with CHD are associated with a twofold increase in mortality from a noncardiac surgery, it is a challenge for the anesthesiologist to handle such patients.

\section{Case Description}

A 3-day-old male weighing $3 \mathrm{~kg}$ was diagnosed with TOF and imperforate anus and was posted for a transverse colostomy. On examination, the baby had a pansystolic murmur, peripheral cyanosis, absent anal opening, distended abdomen, and oxygen saturation of $80 \%$ on $\mathrm{O}_{2}$ with nasal prongs. Hemoglobin was $14 \mathrm{~g} / \mathrm{dL}$ and platelet count was 2 lakhs/cubic millimeter. Two-dimensional echocardiography (2D echo) revealed a hypoplastic right ventricle, large perimembranous VSD with a bidirectional shunt, infundibular valvular stenosis, and a small patent ductus arterosus (PDA) with a left to right shunt. Rest of the routine investigations were normal.

The patient was premedicated with midazolam $0.05 \mathrm{mg} / \mathrm{kg}$ and glycopyrrolate $4 \mu \mathrm{g} / \mathrm{kg}$ intravenously (IV). The patient was induced with sevoflurane, intubated with size 3 uncuffed endotracheal tube and maintained on oxygen, sevoflurane, and atracurium. Caudal analgesia with $1 \mathrm{~mL}$ of $0.5 \%$ bupivacaine + $0.5 \mathrm{~mL}$ of $2 \%$ lignocaine $+1.5 \mu \mathrm{g}$ fentanyl to a total volume of $3 \mathrm{~mL}$ was given. Intraoperative monitoring was done with noninvasive
${ }^{1-3}$ Department of Anaesthesiology, Government Medical College, Miraj, Sangli, Maharashtra, India

${ }^{4}$ Department of Anaesthesiology, BJ Government Medical College, Pune, Maharashtra, India

Corresponding Author: Pradnya M Bhalerao, Department of Anaesthesiology, BJ Government Medical College, Pune, Maharashtra, India, Phone: +91 8806664773, e-mail: dr.pradnyabhalerao@gmail.com

How to cite this article: Indumathi $S$, Kamble $R$, Adsule $P$, et al. Anesthetic Management for Transverse Colostomy in a Neonate with Anorectal Malformation and Uncorrected Tetralogy of Fallot. Res Inno in Anesth 2019;4(1):7-8.

Source of support: Nil

Conflict of interest: None

blood pressure (NIBP), electrocardiogram (ECG), end tidal carbon dioxide $\left(\mathrm{EtCO}_{2}\right)$, and oxygen saturation $\left(\mathrm{SpO}_{2}\right)$. The child began to take good spontaneous respiration at the end of surgery and was extubated while being awake. The postoperative period was uneventful.

\section{Discussion}

The anesthetic management for a noncardiac surgery in a child with TOF necessitates the understanding of its pathophysiology, which is very vital. The severity of disease depends on the degree of right ventricular outflow tract obstruction and VSD. Chronic hypoxia might lead to polycythemia, which may in turn lead to coagulopathy, intracranial abscess, and stroke. ${ }^{2}$

Hours of nil by mouth (NBM) should not be prolonged and it is also important to maintain adequate hydration. Premedication with anxiolytics and sedatives will help us prevent agitation in the child, which will promote a right-to-left shunt and henceforth cyanosis. In case if cyanotic spells occur, phenylephrine 5-10 $\mu \mathrm{g} / \mathrm{kg}$ IV can be given to increase systemic vascular resistance (SVR). Dexmeditomedine $0.2 \mu \mathrm{g} / \mathrm{kg} /$ minute can also be used as it produces analgesia and sedation with less respiratory depression, peripheral vasoconstriction, and also inhibits the release of catecholamines. ${ }^{3}$ Esmolol $0.5 \mathrm{mg} / \mathrm{kg}$ bolus IV followed by $50-300 \mu \mathrm{g} / \mathrm{kg} / \mathrm{minute}$ helps

(c) The Author(s). 2019 Open Access This article is distributed under the terms of the Creative Commons Attribution 4.0 International License (https://creativecommons. org/licenses/by-nc/4.0/), which permits unrestricted use, distribution, and non-commercial reproduction in any medium, provided you give appropriate credit to the original author(s) and the source, provide a link to the Creative Commons license, and indicate if changes were made. The Creative Commons Public Domain Dedication waiver (http://creativecommons.org/publicdomain/zero/1.0/) applies to the data made available in this article, unless otherwise stated. 
reduce infundibular spasm and thereby is used for both prophylaxis and treatment of cyanotic spells. ${ }^{4}$ Treatment of metabolic acidiosis, volume resuscitation, and manual compression of aorta are also to kept in mind during episodes of cyanotic spells.

As TOF is associated with CHARGE 22, VACTERL Syndromes, a difficult intubation should be anticipated. Intravenous or inhalational induction can be done but with careful dose titration. In general, intravenous induction agents are usually preferred in patients with a right-to-left shunt while inhalational agents are used for left-to-right shunts, but it is not a hard-and-fast rule and this is why we need to understand its pathophysiology. In patients with TOF, owing to RVOT obstruction and a right-to-left shunt, which results in decreased pulmonary blood flow, intravenous induction agents are preferred for faster induction.

Ketamine is the most commonly used intravenous induction agent as it increases systemic vascular resistance and propofol is best avoided. ${ }^{5}$ Ketamine in combination with fentanyl can also be used. ${ }^{4}$ But in this case, sevoflurane was preferred as the $2 \mathrm{D}$ echo of the child revealed a patent PDA and there was significant pulmonary blood flow. But careful titration is required to prevent a fall in SVR. ${ }^{7}$

Atracurium is preferred in neonates since the metabolic system is not well established in them, but must be used with caution in view of decreased SVR. Vecuronium can also been used in older children. ${ }^{6}$ Nitrous oxide must be avoided if cardiac function is severely compromised as it increases pulmonary vascular resistance (PVR).

Increase in PVR will promote a left-to-right shunt, while a fall in SVR will decrease blood pressure. Hence a balance between them is essential. ${ }^{7}$ Factors increasing PVR such as hypoxia, hypercapnea, hyperthermia, inadequate depth of anesthesia, acidosis, and positive end expiratory pressure should be avoided.

Not all patients with TOF experience cyanotic spells. There are some mild cases referred to as pink tet in which RVOT obstruction and VSD is not severe or there may be a patent ductus arteriosus promoting pulmonary flow. Hence it is important in those cases to keep the duct patent. NSAIDS that will promote the closure of PDA should be avoided. Intravenous prostaglandin E1 $0.05-0.2 \mu \mathrm{g} / \mathrm{kg} /$ minute will prevent the closure of ductus arteriosus. ${ }^{8}$

Pain is one more factor that can aggravate cyanotic spells postoperatively. Hence, postoperative analgesia is necessary.
In this case, caudal analgesia with opioid was given. Regional blocks appropriate for the case can be preferred. ${ }^{9}$

Complications such as air embolism, arrhythmia, cyanotic attack, congestive cardiac failure, and right ventricular dysfunction must be anticipated and should be treated accordingly.

\section{Conclusion}

Successful anesthetic management for a noncardiac surgery in patients with TOF depends on the knowledge of pathophysiology of TOF, effective evaluation, appropriate preparation, and management of the case.

\section{References}

1. Brien OP, Marshall CA. Tetralogy of fallot. Circulation 2014;130(4): 26-29.

2. Manuel V, Matias E, Morais $\mathrm{H}$, et al. Brain Abscess in Uncorrected Tetralogy of Fallot Diagnosed during Preparation for Computed Cardiac Angiotomography. J Cardiovasc Dis Diagn 2015;3(2): $1-2$.

3. Wajekar AS, Shetty AN, Oak SP, et al. Anaesthetic management for drainage of fronto parietal abscess in a patient of uncorrected tetralogy of fallot. Indian J Anaesth 2015;1(59):244-246. DOI: 10.4103/0019-5049.155003.

4. Saikia P, Talukdar FA, Phukan B, et al. Repair of Right Bochdalek hernia in a patient with uncorrected tetralogy of fallot: Anaesthetic management. Indian J Anaesth 2015;59(11):756-758. DOI: 10.4103/0019-5049.170041.

5. Michelle CM, James MP. Anaesthetic management of children with congenital heart disease for non-cardiac surgery, Continuing Education in Anesthesia Critical care and pain. British J Anaesth 2012;12:17-22.

6. Sharma A, Swami A, Chala M. Non cardiac surgery in a child after palliative surgical repair of tetralogy of fallot. Anaesth Pain \& Intensive Care 2014;18(4):467-468.

7. Hines RL, et al. Stoelting's anesthesia and coexisting diseases, 7th ed., Philadelphia: Elsevier; 2017. p. 138.

8. Talosi G, Katona M, Racz K, et al. Prostaglandin E1 treatment in patent ductusarteriosus dependent congenital heart defects. J Perinat Med 2004;32(4):368-374. DOI: 10.1515/JPM.2004.069.

9. Sethi S, Kapil S. Scalp block for brain abscess drainage in a patient with uncorrected TOF. World J Clin Cases 2014;2(12):934-937. DOI: 10.12998/wjcc.v2.i12.934. 